\title{
Profile Of Cardiac Arrhythmia In Nepalese Population By Ambulatory Electrocardiogram Analysis
}

\author{
A. B. Upadhyaya, *R. K. Shah, P. A. Regmi, T. N. Bhattarai, R.R. Paudel, \\ U. K. Shrestha, K.P Acharya, H. H. Khanal, D, Shrestha
}

\section{Background}

Effective management of Cardiac arrhythmias and conduction disturbances requires accurate identification of the specific rhythm disturbances, analysis of the clinical settings in which they occur and identification of a safe and effective endpoint of therapy. Some arrhythmias are hazardous to the patient regardless of the clinical Settings (e.g. ventricular fibrillation), where as others are hazardous because of the clinical settings (e.g. rapidly conducted atrial librillation in patient with severe coronary artery stenosis) Present study aims al determining profile of cardiac arrhythmias in patients, attending a private hospital.

\section{Materials And Methods}

A Retrospective Analysis done in 2462 patients, presented at Medicare National Hospital And Research Center for Ambulatory Electrocardiogram (ECG). Since January 1999 to December 2003. The data was analyzed and various cardiac arrhythmias were stratified.

\section{Result}

Out of 2462 patients Males were $1524(61.90 \%)$ and Female were $938(38.10 \%)$ patient age ranges from 12 to 82 years. Female and Male ratio was 1: 1.6. Combined Mean age of patient was 51.56 years. Normal Ambulatory ECG found in $639(25.95 \%)$ where as abnormal Ambulatory ECG in $1823(74.05 \%)$. Premature ventricular contractions (VPCS) was found in $695(28.23 \%)$ premature atrial contractions (APCS) found in 359 (14.58\%), atrial fibrillation in 93 (3.78\%), paroxysmal supraventricular tachycardia (PSVT) in $32(1.30 \%)$, third degree atrioventricular block in $42(1.70 \%)$ first and second degree atrioventricular block in 94 (3.82\%) and ventricular tachycardia (VT) in 70 (2.84\%). 
- NEPALESE HEART JOURNAL •

\section{Conclusion}

- VPC was most common Cardiac arrhythmia.

- VT'was not uncommon during routine Ambulatory ECG analysis.

- Ventricular fibrillation was not recorded.

- Various types of AV block were commonly seen. 